\title{
Template-Free Synthesis of Ordered Mesoporous NiO/Poly (Sodium-4-Styrene Sulfonate) Functionalized Carbon Nanotubes Composite for Electrochemical Capacitors
}

\author{
Changzhou Yuan, Shenglin Xiong, Xiaogang Zhang ( $\varangle)$, Laifa Shen, Fang Zhang, Bao Gao, and Linhao Su \\ College of Material Science \& Engineering, Nanjing University of Aeronautics and Astronautics, Nanjing 210016, China \\ Received: 22 June 2009 / Revised: 2 August 2009 / Accepted: 13 August 2009 \\ (CTsinghua University Press and Springer-Verlag 2009. This article is published with open access at Springerlink.com
}

\begin{abstract}
We report the first example of a practical and efficient template-free strategy for synthesizing ordered mesoporous $\mathrm{NiO} /$ poly(sodium-4-styrene sulfonate) (PSS) functionalized carbon nanotubes (FCNTs) composites by calcining a $\mathrm{Ni}(\mathrm{OH})_{2} /$ FCNTs precursor prepared by refluxing an alkaline solution of $\mathrm{Ni}\left(\mathrm{NH}_{3}\right)_{x}{ }^{2+}$ and FCNTs at $97^{\circ} \mathrm{C}$ for $1 \mathrm{~h}$. The morphology and structure were characterized by X-ray diffraction, scanning electron microscopy, and transmission electron microscopy. Thermal decomposition of the precursor results in the formation of ordered mesoporous $\mathrm{NiO} /$ FCNTs composite (ca. $48 \mathrm{wt} \% \mathrm{NiO}$ ) with large specific surface area. Due to its enhanced electronic conductivity and hierarchical (meso- and macro-) porosity, composite simultaneously meets the three requirements for energy storage in electrochemical capacitors at high rate, namely, good electron conductivity, highly accessibleelectrochemical surface areas owing to the existence of mesopores, and efficient mass transport from the macropores. Electrochemical data demonstrated that the ordered mesoporous $\mathrm{NiO} / \mathrm{FCNTs}$ composite is capable of delivering a specific capacitance (SC) of $526 \mathrm{~F} / \mathrm{g}$ at $1 \mathrm{~A} / \mathrm{g}$ and a SC of $439 \mathrm{~F} / \mathrm{g}$ even at $6 \mathrm{~A} / \mathrm{g}$, and show a degradation of only ca. $6 \%$ in SC after 2000 continuous charge/ discharge cycles.
\end{abstract}

\section{KEYWORDS}

Template-free, ordered mesopores, $\mathrm{NiO} /$ carbon nanotubes composite, hierarchical porosity, electrochemical supercapacitors

Pseudocapacitance has been studied for various metal oxides, such as $\mathrm{RuO}_{2}[1,2], \mathrm{CoO}_{x}[3,4], \mathrm{NiO}[5$ $-10]$, and $\mathrm{MnO}_{2}$ [11-13], due to their higher specific capacitance (SC) compared to carbon-based materials [1-13] and better stability than conducting polymers [14]. In particular, $\mathrm{NiO}$ enjoys a special place due to its easy availability, environmentally benign nature, cost effectiveness, and good pseudocapacitive behavior. Unfortunately, there are still some obstacles to its practical application due to its low observed SC [5-10], considering its theoretical value (2573 F/g within $0.5 \mathrm{~V})[5,6]$.

The key strategy is to maximize the electrochemical utilization of the $\mathrm{NiO}$ phase. Pseudocapacitance is an interfacial phenomenon related to the specific surface area (SSA) of electroactive materials and involving

Address correspondence to azhangxg@163.com 
charge transfer through surface Faradaic reactions [15]. Moreover, to obtain high-energy density at larger current densities, it is necessary to fabricate materials with a hierarchical (meso- and macro-) porous structure. The mesoporous structure affords high SSA and electrochemical energy storage of the electroactive material [3], whilst the macropores can absorb and strongly retain electrolyte ions, which ensures sufficient Faradaic reactions take place at high current densities [16]. Therefore, the development of effective ways to enhance the electronic conductivity and the SSA of NiO phases with hierarchical porosities are of great significance for the nextgeneration electrochemical capacitors (ECs).

Recently, carbon nanotubes (CNTs)-based NiO composites have been studied $[17,18]$ and are expected to show improved capacitance owing to their enhanced electronic conductivity, due to the CNTs substrate [13, 17-20]. However, their aggregation in most solvents, which may greatly hamper their widespread use [21], has triggered attempts to modify their surface before practical application. Recently, anionic poly(sodium-4styrene sulfonate) (PSS) has been used to functionalize CNTs, since it can not only solubilize CNTs effectively in aqueous solution but also noncovalently functionalize CNTs [22-25]. Sidewall functionalization of CNTs with negatively charged PSS can create many more electroactive sites that can tether ions with positive charge for subsequent oriented growth of metal oxide along the CNTs, as verified by our previous work $[2,11,23]$. Only in this way, can CNTs maintain three-dimensionally interconnected and unblocked pore structures on the nanometer scale, which allows them to retain the ability to absorb and facilitate the transport of electrolyte ions through the remaining porous channels within the composite even in the case of high loadings.

In order to obtain $\mathrm{NiO}$ with larger SSA, porous structures have been widely studied. Recently, the extension of the soft or/and hard templating procedure to the formation of porous $\mathrm{NiO}$ with large SSA has attracted great attention [7-10]. However, all of these need a template or structure-directing agent, increasing their production cost and complexity. Therefore, it is worthwhile to develop easily controlled methods obviating the need for templates to prepare $\mathrm{NiO}$ with high porosity.

In the present work, we propose the first facile and template-free strategy to synthesize ordered mesoporous $\mathrm{NiO}$ grown along PSS-functionalized CNTs (FCNTs), which avoids the subsequent complicated workup procedure for removing the template or seed. Electrochemical data demonstrate that the ordered mesoporous $\mathrm{NiO} / \mathrm{FCNT}$ composite (ca. $48 \mathrm{wt} \% \mathrm{NiO}$ ) with hierarchical porosity and large SSA can deliver large energy density and good electrochemical stability at high rates, suggesting their feasible application for ECs.

\section{Experimental}

\subsection{Sample preparation}

The PSS-functionalized CNTs can be obtained by the same method as we reported earlier [2,23]. Nickel nitrate $\left(\mathrm{Ni}\left(\mathrm{NO}_{3}\right)_{2} \cdot 6 \mathrm{H}_{2} \mathrm{O}\right)$ and aqueous ammonia $\left(\mathrm{NH}_{3} \cdot \mathrm{H}_{2} \mathrm{O}\right)(28 \%-30 \%)$ were of analytical grade and used as purchased without further purification. Deionized water was used as the solvent in all the experiments. In a typical synthesis run [26], $200 \mathrm{mg}$ of PSS-functionalized CNTs were dispersed well in $50 \mathrm{~mL}$ of deionized water, which was then mixed with $50 \mathrm{~mL}$ of ammonia solution in a $500 \mathrm{~mL}$ threenecked flask with a reflux condenser mounted on top, which was then immersed in an oil bath at ca. $97{ }^{\circ} \mathrm{C}$. After heating for ca. $10 \mathrm{~min}$ under constant magnetic stirring, $20 \mathrm{~mL}$ of $1.0 \mathrm{~mol} / \mathrm{L} \mathrm{Ni}\left(\mathrm{NO}_{3}\right)_{2} \cdot 6 \mathrm{H}_{2} \mathrm{O}$ was added dropwise within ca. 2 min. The reaction was continued for $60 \mathrm{~min}$ (timing started with the addition of nickel nitrate) before the flask was taken out of the oil bath and allowed to cool in room air. The solid green product was harvested by centrifugation, washed with deionized water several times before drying at $50{ }^{\circ} \mathrm{C}$ in an oven overnight. Subsequently, the $\mathrm{NiO} / \mathrm{FCNT}$ composite was calcined in air at $300{ }^{\circ} \mathrm{C}$ for $2 \mathrm{~h}$ with a temperature ramp of $1{ }^{\circ} \mathrm{C}$ per min. To obtain the accurate the amount of $\mathrm{NiO}$ in the composite, the sample was stirred in $2 \mathrm{~mol} / \mathrm{L} \mathrm{HCl}$ for $24 \mathrm{~h}$ to remove the $\mathrm{NiO}$ completely. The calculated amount of $\mathrm{NiO}$ in the composite was ca. $48 \mathrm{wt} \%$. For comparison, the $\mathrm{NiO} / \mathrm{CNTs}$ composite with the same 
$\mathrm{NiO}$ loading was also synthesized using the same procedure with unmodfiied CNTs as a support.

\subsection{Electrode preparation}

The working electrode was prepared by mixing $85 \mathrm{wt} \%$ of the synthesized NiO/FCNTs composite (or NiO/CNTs composite or FCNTs), $10 \mathrm{wt} \%$ of acetylene black, and $5 \mathrm{wt} \%$ of poly(tetrafluoroethyle ne), and pressing (20 MPa) the mixture onto a nickel grid $\left(1 \mathrm{~cm}^{2}\right)$.

\subsection{Material characterization}

The morphologies of the samples were examined by transmission electron microscopy (TEM, FEI, Tecnai-20, USA) and by scanning electron microscopy (SEM, LEO 1430VP, Germany). The X-ray diffraction (XRD) patterns of the samples were observed by XRD (Max 18 XCE, Japan) using a $\mathrm{Cu} \mathrm{Ka}$ source and energy dispersive analysis by X-ray (EDAX, Link-200, UK). $\mathrm{N}_{2}$ adsorption/desorption isotherms were determined using an ASAP-2010 surface area analyzer. The electrical conductivities of the synthesized samples were evaluated by a four-point probe meter (SDY, Guangzhou, China).

\subsection{Electrochemical evaluation}

The electrochemical measurements were carried out by means of an electrochemical analyzer system, CHI660B (Chenhua, Shanghai, China), in a three-compartment cell with a working electrode, a platinum plate counter electrode, and a saturated calomel electrode (SCE) reference electrode. The electrolyte was a $6 \mathrm{~mol} / \mathrm{L}$ $\mathrm{KOH}$ aqueous solution. The SCs of the composites were calculated from the chronopotentiometry (CP) curves based on Eq. (1):

$$
\mathrm{SC}=\frac{I t}{\Delta V}
$$

where SC, $I, t$, and $\Delta V$ are the specific capacitance $(\mathrm{F} / \mathrm{g})$ of the electrode, the current density $(\mathrm{A} / \mathrm{g})$ used for charge/discharge, the time (s) elapsed for the charge or discharge cycles, and the potential interval (V) of the charge or discharge, respectively. Another important parameter, coulombic efficiency $(\eta)$, can be evaluated from the Eq. (2):

$$
\eta=\frac{t_{\mathrm{D}}}{t_{\mathrm{C}}} \times 100 \%
$$

where $t_{\mathrm{D}}$ and $t_{\mathrm{C}}$ are the time for galvanostatic discharging and charging, respectively. The high-rate dischargeability (HRD) of the electrode was defined as the ratio of discharge capacitance at a certain density to that of $1 \mathrm{~A} / \mathrm{g}$ and calculated according to the following formula:

$$
\operatorname{HRD}(\%)=\frac{\mathrm{SC}_{\mathrm{d}}}{\mathrm{SC}_{1}} \times 100
$$

where $\mathrm{SC}_{\mathrm{d}}$ and $\mathrm{SC}_{1}$ are the discharge $\mathrm{SC}$ s of the electrode at a certain current density and $1 \mathrm{~A} / \mathrm{g}$, respectively.

\section{Results and discussion}

\subsection{Structure analysis and formation mechanism of the ordered mesoporous $\mathrm{NiO} / \mathrm{FCNTs}$ composite}

The XRD pattern of the as-prepared $\mathrm{Ni}(\mathrm{OH})_{2} /$ FCNTs precursor is shown in Fig. 1(a). Eight obvious diffraction peaks are present and can be assigned to the hexagonal phase of $\beta-\mathrm{Ni}(\mathrm{OH})_{2}$ (JCPDS, No. 14-0117) with lattice parameters of $a=3.126 \AA$ and $c=4.605 \AA$ and a space group of $P-3 m 1$ [No. 164]. Moreover, as indicated by the solid black circles, the diffraction peak at $2 \theta$ of ca. $26^{\circ}$ is ascribed to the (002) reflections of FCNTs, whose relative intensity is very low due to the dominant and strong contribution from $\mathrm{Ni}(\mathrm{OH})_{2}$ with good crystallinity. After the thermal decomposition of the precursor, a $\mathrm{NiO} /$

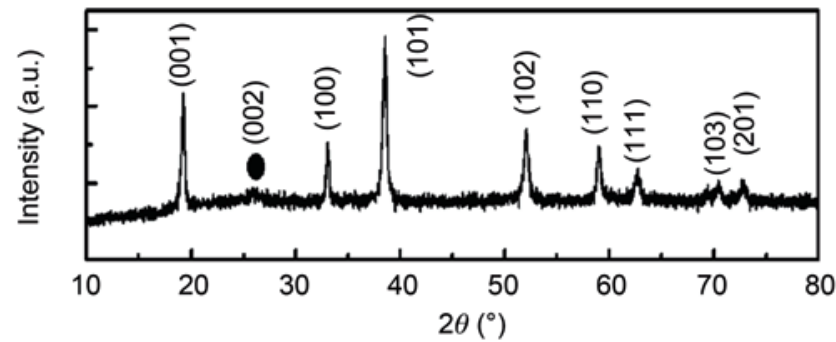

(a)

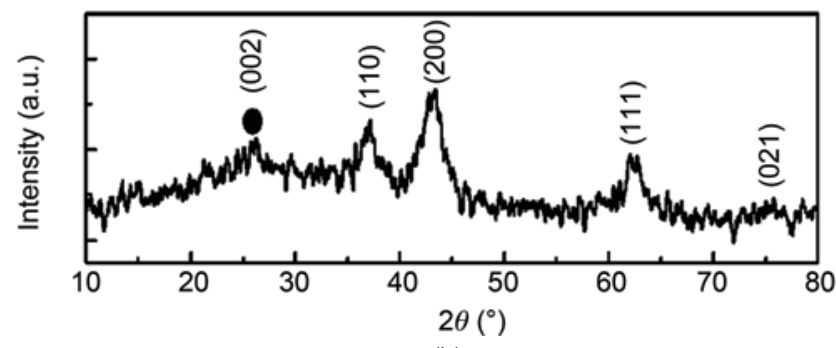

(b)

Figure 1 XRD patterns of the $\mathrm{Ni}(\mathrm{OH})_{2} / \mathrm{FCNTS}(\mathrm{a})$ and NiO/FCNTs (b) composites 

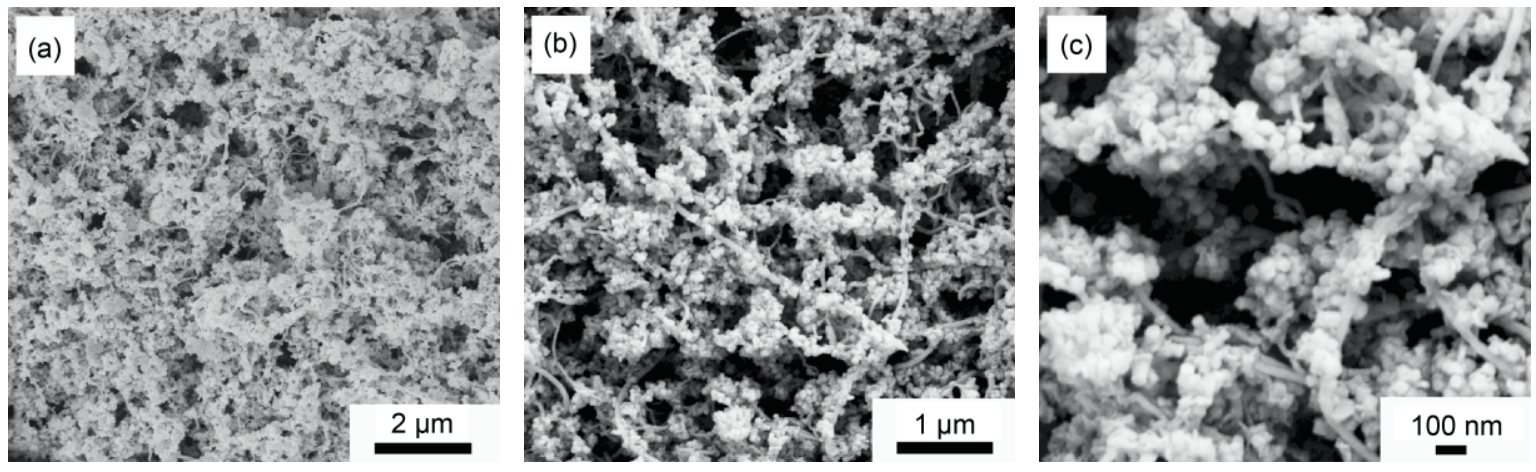

Figure 2 SEM images of the NiO/FCNTs composite with different magnifications

FCNTs composite was obtained. Figure 1(b) displays the XRD pattern of the synthesized NiO/FCNTs composite. Apart from the peak contributed by FCNTs in Fig. 1 (b) all the reflections, including not only the peak position but also their relative intensities, can be indexed to the monoclinic $\mathrm{NiO}$ phase crystalline structure, in line with the standard pattern (JCPDS 65-6920; space group:C2/m [12]).

Figure 2 (a) displays the SEM image of the $\mathrm{NiO} /$ FCNTs composite, in which a good dispersion of "island-like" $\mathrm{NiO}$ nanoparticles can be seen on the surfaces of the FCNTs. From the higher magnification images (Figs. 2 (b) and 2(c)), it can be seen that the $\mathrm{NiO}$ nanoparticles are preferentially tethered onto the surfaces of, and grown along, the FCNTs, like some beautiful "flowers" on trees. Thereby, a good threedimensional porous structure with its interconnected pores remaining unblocked by the $\mathrm{NiO}$ nanoparticles to some extent is obtained. Such a structure favors diffusion of the electrolyte ions into the composite through these three-dimensional pores to contact fresh electroactive $\mathrm{NiO}$ phase giving enhanced energy storage. In addition, the morphology of $\mathrm{NiO}$ is the same as that of its precursor (Fig. 3), which indicates that the desired nanostructure can be obtained via a simple thermal decomposition of this precursor.

For comparison, Fig. 4 demonstrates the SEM image of the $\mathrm{NiO} / \mathrm{CNT}$ composite with the same $\mathrm{NiO}$ loading. Clearly, its morphology and microstructure are drastically different from those of the NiO/FCNTs composite presented in Fig. 2. Large aggregations of $\mathrm{NiO}$ nanoparticles and the CNTs co-exist in the product. Such aggregations will be expected to block the interconnected pores to a significant extent, which will greatly restrain the diffusion of electrolyte ions

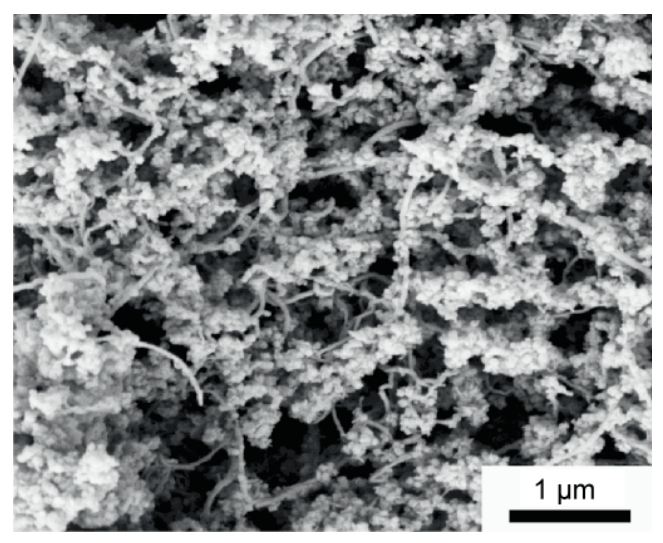

Figure 3 SEM image of the $\mathrm{Ni}(\mathrm{OH})_{2} /$ FCNTs composite

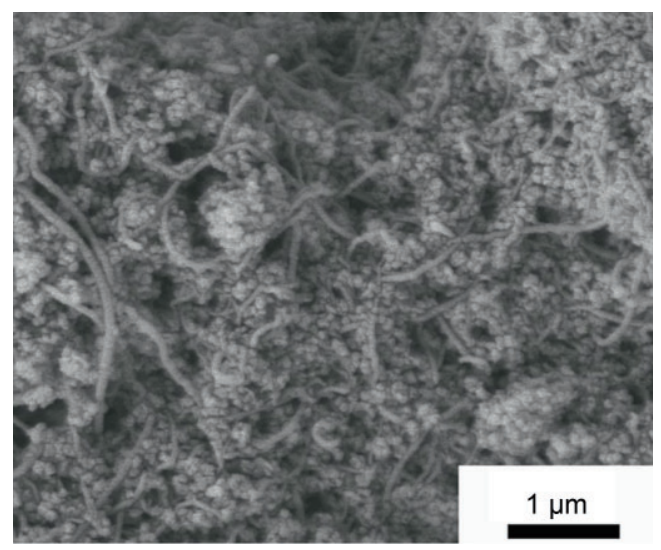

Figure 4 SEM image of the NiO/CNTs composite

into the composite and thus hinder the occurrence of electrochemical reactions for energy storage, particularly in the case of larger current densities. Furthermore, it is worth noting the different morphologies present when the same procedure is employed using CNTs instead of FCNTs. Therefore, it is apparent that PSS plays a great role in facilitating the oriented growth of $\mathrm{NiO}$ along the FCNTs, due to the strong interaction between the $\mathrm{NiO}$ and FCNTs.

During the refluxing process, the high $\mathrm{pH}$ favors

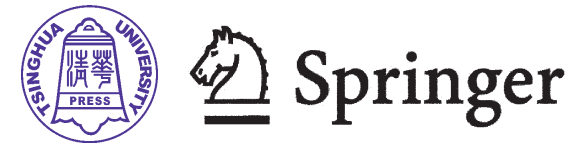


the formation of the $\mathrm{Ni}(\mathrm{OH})_{2}$ phase, which can be described as follows:

$$
\begin{aligned}
& \mathrm{Ni}^{2+}+\mathrm{NH}_{3} \cdot \mathrm{H}_{2} \mathrm{O} \rightarrow\left[\mathrm{Ni}\left(\mathrm{NH}_{3}\right)_{y}\right]^{2+}+y \mathrm{H}_{2} \mathrm{O} \\
& {\left[\mathrm{Ni}\left(\mathrm{NH}_{3}\right)_{y}\right]^{2+} \stackrel{\text { refluxing }}{\longrightarrow} \mathrm{Ni}^{2+}+y \mathrm{NH}_{3}} \\
& \mathrm{NH}_{3} \cdot \mathrm{H}_{2} \mathrm{O} \stackrel{\text { refluxing }}{\longrightarrow} \mathrm{NH}_{4}^{+}+\mathrm{OH}^{-} \\
& \mathrm{Ni}^{2+}+2 \mathrm{OH}^{- \text {refluxing }} \longrightarrow \mathrm{Ni}(\mathrm{OH})_{2}
\end{aligned}
$$

The $\left[\mathrm{Ni}\left(\mathrm{NH}_{3}\right)_{y}\right]^{2+}$ ions with their positive charge can be adsorbed and tethered at the surfaces of the FCNTs bearing a negative charge, due to the electrostatic interaction. During the refluxing process, the $\mathrm{Ni}(\mathrm{OH})_{2}$ phase will grow along the FCNTs. After calcination at $300{ }^{\circ} \mathrm{C}$ for $2 \mathrm{~h}$, the $\mathrm{Ni}(\mathrm{OH})_{2}$ becomes $\mathrm{NiO}$ according to Eq. (8), and consequently, the resulting $\mathrm{NiO}$ also grows along the FCNTs.

$$
\mathrm{Ni}(\mathrm{OH})_{2} \stackrel{\text { endothermic }}{\longrightarrow} \mathrm{NiO}+\mathrm{H}_{2} \mathrm{O}
$$

The microstructure of the synthesized $\mathrm{NiO} /$ FCNTs composite was further characterized by TEM, as shown in Fig. 5. From Fig. 5(a), it is evident that the $\mathrm{NiO}$ nanoparticles mostly retain a quadrate morphology (indicated by the red squares) with a length of 50-70 $\mathrm{nm}$ and a width of 30-60 nm. Moreover, the higher-magnification TEM image (Fig. 5(b)) clearly demonstrates that the $\mathrm{NiO}$ phase has ordered mesoporous channels of ca. 3-4 nm diameter. Such nanoscale size can guarantee that the electrolyte ions will diffuse easily into the ordered channels to contact its surface area very effectively, and subsequently, more redox Faradaic reactions will take place enhancing electrochemical energy storage. The EDAX spectrum, shown in Fig. 5(c), reveals the existence of $\mathrm{C}, \mathrm{Ni}, \mathrm{O}$, and $\mathrm{S}$ species. Whilst the $\mathrm{C}, \mathrm{Ni}$, and $\mathrm{O}$ elements are expected from CNTs and $\mathrm{NiO}$ phases, the presence of $S$ element reveals the vestiges of the PSS in the synthesized nanocomposite. It should be emphasized that no templates or structuredirecting agents are required in the synthesis process of the $\mathrm{NiO} / \mathrm{FCNTs}$ composite to facilitate the formation of mesopores. However, an ordered mesoporous structure of $\mathrm{NiO}$ is unexpectedly formed. This raises the question of whether the ordered mesoporous structure of the $\mathrm{NiO}$ only forms during the calcination or whether it is reflecting the mesoporous structure of its precursor $\mathrm{Ni}(\mathrm{OH})_{2}$.

To answer this question, TEM images with
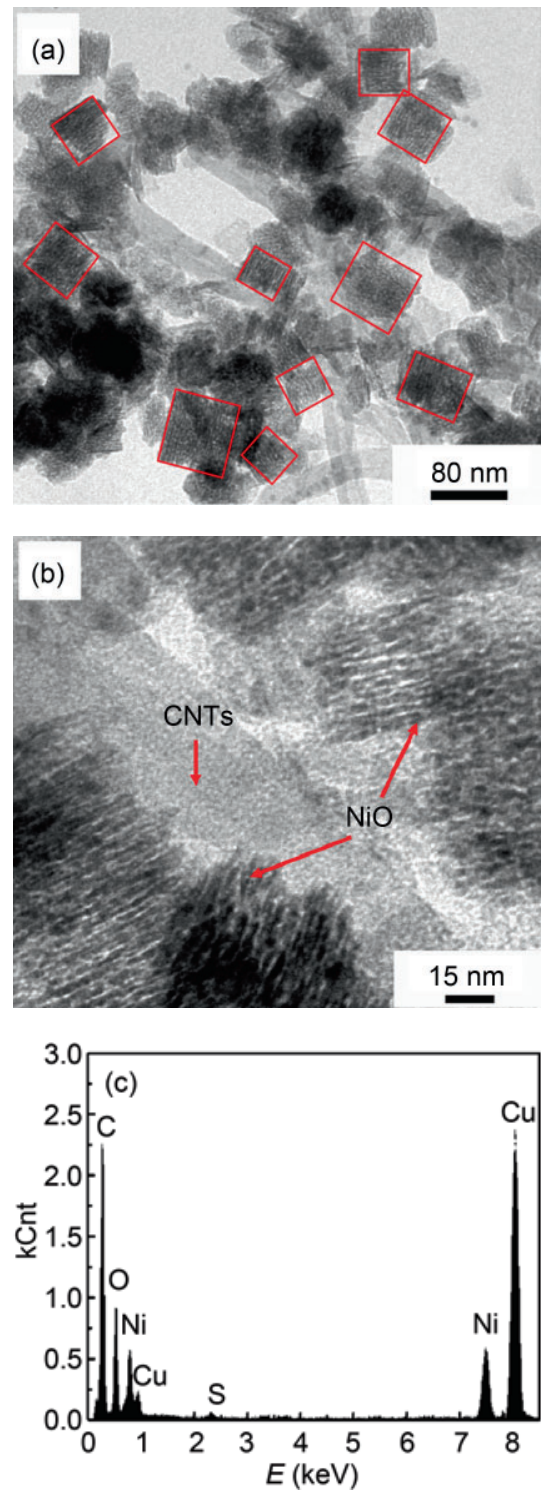

Figure 5 TEM images ((a) and (b)) of the NiO/FCNTs composite with different magnifications and the EDAX results (c)

different magnification of the $\mathrm{Ni}(\mathrm{OH})_{2} /$ FCNTs composite are depicted in Fig. 6. Clearly, from Figs. $6(\mathrm{a})$ and $6(\mathrm{~b})$, the morphology of $\mathrm{Ni}(\mathrm{OH})_{2}$ is the same as that of $\mathrm{NiO}$ shown in Fig. 5(a), revealing that the calcination process has no influence on the morphology of the samples. However, its highermagnification image (Fig. 6(c)) does not present the ordered mesoporous channels, indicating the great effect of the calcination process on the microstructure of the samples, due to the dehydration occurring during calcination at $300{ }^{\circ} \mathrm{C}$. Therefore, the only interpretation is that the formation of the ordered mesoporous $\mathrm{NiO}$ is related to the thermal 

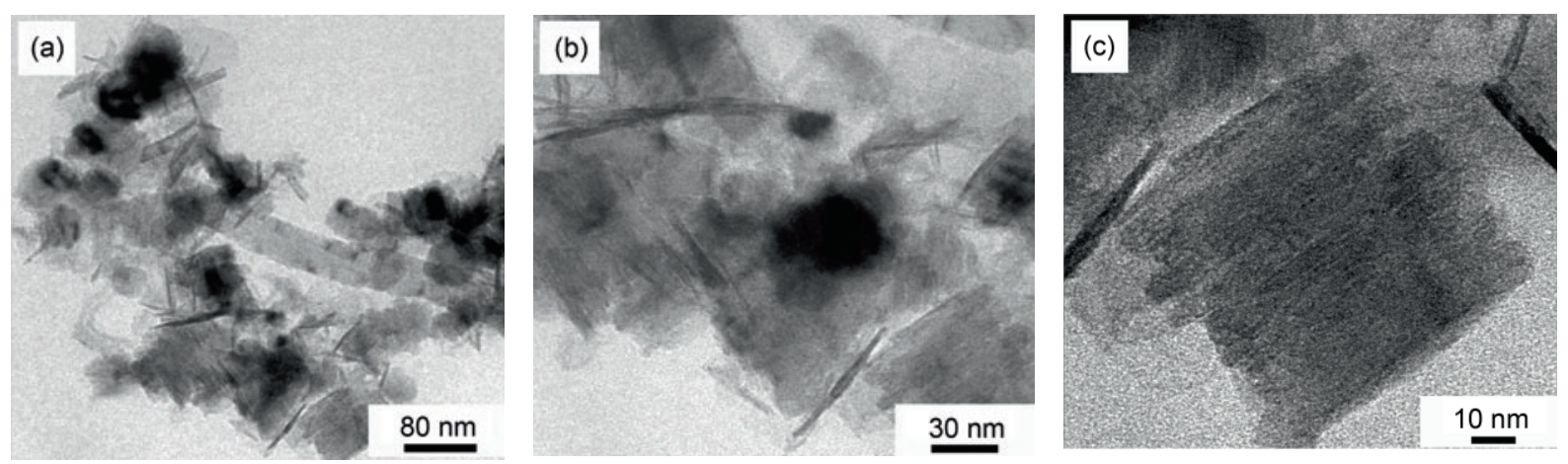

Figure 6 TEM images of the Ni(OH)/ $/$ FCNTs composite with different magnification

decomposition process. It is well known that nickel oxide can become porous via thermal decomposition of $\beta-\mathrm{Ni}(\mathrm{OH})_{2}$, although some products with unchanged nanostructure can be obtained due to the dehydration process [27].

Figure 7 displays the $\mathrm{N}_{2}$ adsorption-desorption isotherms and Barrett-Joyner-Halenda (BJH) pore size distribution of the $\mathrm{NiO} / \mathrm{FCNTs}$ composite. In terms of $\mathrm{N}_{2}$ adsorption-desorption isotherms (Fig. 7 (a)), the synthesized $\mathrm{NiO} /$ FCNTs composite can

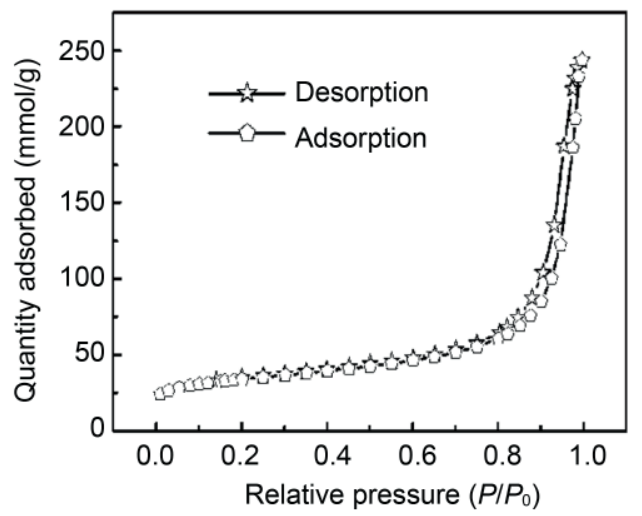

(a)

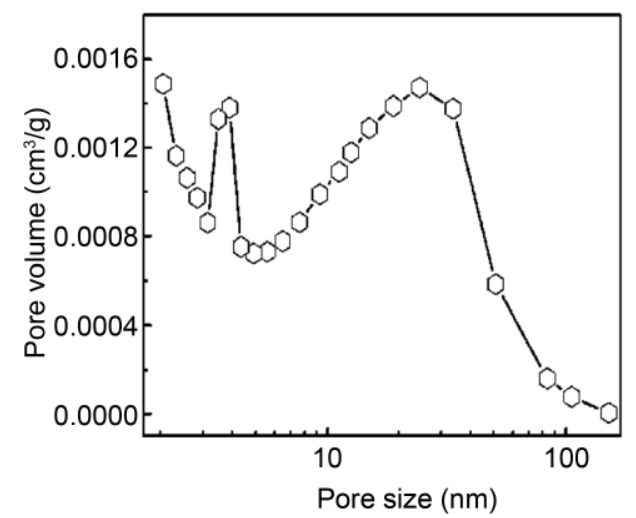

(b)

Figure 7 Gas $\left(\mathrm{N}_{2}\right)$ adsorption-desorption isotherm hysteresis loop (a) and histogram of the pore size distribution (PSD) data (b) for the NiO/FCNTs composite be classified as type IV according to the IUPAC classification. A distinct hysteresis loop can be observed in the larger pressure range of ca. $0.8-$ $1.0 P / P_{0}$, indicating the presence of macropores $[28,29]$. The BJH pore size distribution (Fig. $7($ b)) further reveals the presence of the multi-modal and hierarchical porosity, with mesopores together with macropores. The peaks at ca. $3.7 \mathrm{~nm}$ are mainly contributed by the pores existing in the $\mathrm{NiO}$ phase in the composite, whilst the peaks between 20 and $100 \mathrm{~nm}$ can be related to the pores in and between the interconnected FCNTs. Their textural properties are as follows: a Brunauer-Emmett-Teller (BET) SSA of $230 \mathrm{~m}^{2} / \mathrm{g}$ including an external SSA of 219 $\mathrm{m}^{2} / \mathrm{g}$, mesoporous volume of $0.72 \mathrm{~cm}^{3} / \mathrm{g}$, and an average pore size of ca. $14 \mathrm{~nm}$. Such large SSA and hierarchical porosity of the $\mathrm{NiO} / \mathrm{FCNTs}$ should result in their good electrochemical performance, because the material combines the excellent performance of efficient mass transport from macropores with the advantages of highly accessible and electrochemical surface areas due to the existence of mesopores.

\subsection{Electrochemical performance of the ordered mesoporous NiO/FCNTs composite}

Figure 8(a) shows cyclic voltammograms (CV) at various scan rates for the $\mathrm{NiO} / \mathrm{FCNT}$ composite electrode recorded between 0.0 and $0.6 \mathrm{~V}$ (vs $\mathrm{SCE}$ ) in $6 \mathrm{~mol} / \mathrm{L} \mathrm{KOH}$ aqueous electrolyte. The electrochemical response currents of the $\mathrm{CV}$ curves on the positive sweeps are nearly mirror-image symmetric to their corresponding counterparts on the negative sweeps with respect to the zero-current line. As the scan rate increases from 2 to $20 \mathrm{mV} / \mathrm{s}$, the current subsequently increases while the shape 


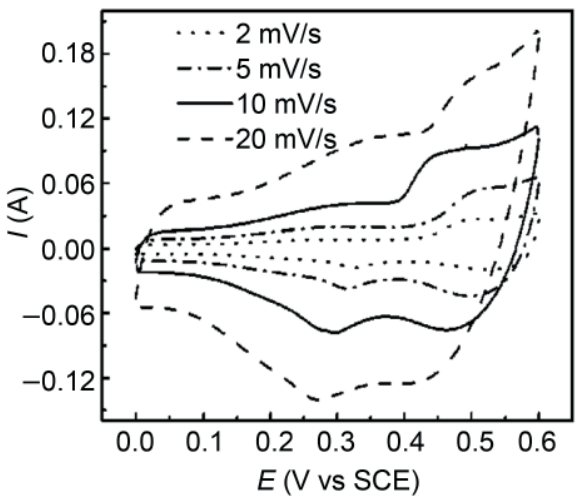

(a)

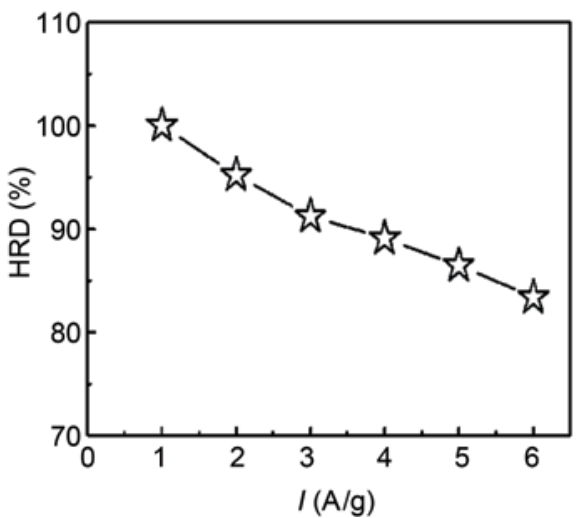

(c)

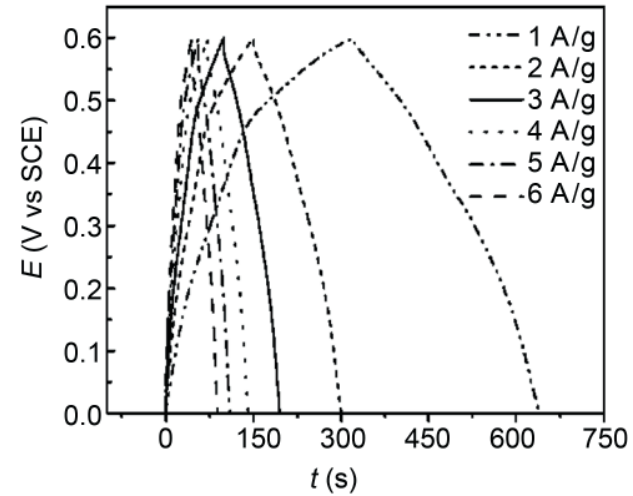

(b)

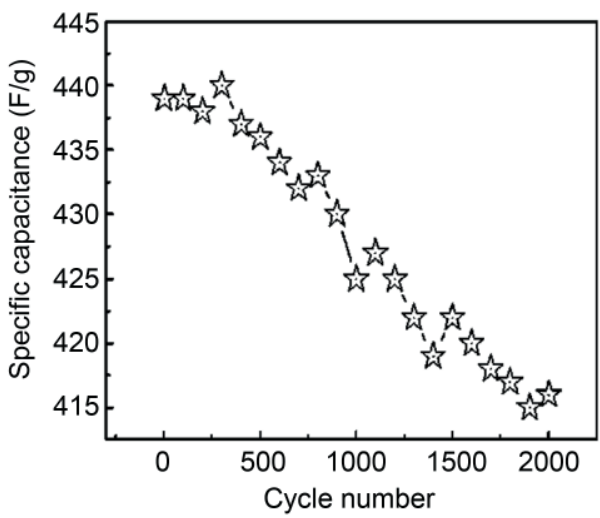

(d)

Figure 8 CV curves (a), CP plots (b), HRD (c), and cycle life (d) of the NiO/FCNTs composite

of CV curves changes little and very rapid current responses on voltage reversal occur at each end potential, even at $20 \mathrm{mV} / \mathrm{s}$, which indicates good electrochemical capacitive nature for the composite in $6 \mathrm{~mol} / \mathrm{L} \mathrm{KOH}$ electrolyte. The obvious redox peaks within the potential range from 0.2 to $0.6 \mathrm{~V}$ result mainly from the pseudocapacitive character based on the surface Faradaic redox mechanism of $\mathrm{Ni}^{2+}$ to $\mathrm{Ni}^{3+}$ occurring at the surface of $\mathrm{NiO}$ according to the following equation:

$$
\mathrm{NiO}^{+} \mathrm{OH}^{-} \underset{\text { discharge }}{\text { charg }} \mathrm{NiOOH}+\mathrm{e}^{-}
$$

Figure 8 (b) shows the galvanostatic constant current charge-discharge curves of the composite at different current densities within an electrochemical window from 0.0 to $0.6 \mathrm{~V}$ (vs SCE). A symmetric triangular shape during the charge-discharge processes is observed, which resembles those of electrochemical double layer capacitors. However, a closer look indicates that the slopes of the gavanostatic charge-discharge curves slightly differ from linearity as a result of the pseudo-Faradaic processes for the electrode. The SCs and coulombic efficiencies of the composite at various current densities can be calculated based on the charge-discharge curves in Fig. 8(b) according to Eqs. (1) and (2), respectively, and typical data are shown in Table 1.

Evidently, the coulombic efficiencies at different current densities are all more than $98 \%$. Moreover, the coulombic efficiency can be up to $100 \%$ when the current densities are not less than $4 \mathrm{~A} / \mathrm{g}$, revealing the good electrochemical reversibility of the composite. More impressively, an SC of $526 \mathrm{~F} / \mathrm{g}$ can be delivered by the composite at $1 \mathrm{~A} / \mathrm{g}$, and $439 \mathrm{~F} / \mathrm{g}$ even at 6 A/g. Considering the mass (ca. $48 \mathrm{wt} \%$ ) of $\mathrm{NiO}$ in the composite, an SC of ca. $1096 \mathrm{~F} / \mathrm{g}(1 \mathrm{~A} / \mathrm{g})$ contributed by the $\mathrm{NiO}$ phase, indicates a good electrochemical utilization of the electroactive $\mathrm{NiO}$ in the composite. The composite not only exhibits high SCs but also maintains them well at higher current densities. Specifically, as the current density increases to $6 \mathrm{~A} / \mathrm{g}$, the composite preserves more than $83 \%$ of its SC delivered at $1 \mathrm{~A} / \mathrm{g}$ as shown by the high rate dischargeability (HRD) plot in Fig. 8(c). The data indicate that the NiO/FCNTs composite is a good electroactive material for ECs application, due to its ability to provide high-energy density at a high charge/discharge rate. The cyclability of the composite in $6 \mathrm{~mol} / \mathrm{L} \mathrm{KOH}$ electrolyte is one of the

Table 1 SCs and coulombic efficiency $(\eta)$ of the NiO/FCNTS composite at different current densities

\begin{tabular}{lllllll}
\hline$I(\mathrm{~A} / \mathrm{g})$ & 1 & 2 & 3 & 4 & 5 & 6 \\
\hline $\mathrm{SC}(\mathrm{F} / \mathrm{g})$ & 526 & 501 & 480 & 469 & 455 & 439 \\
\hline$\eta(\%)$ & 98 & 99 & 99 & 100 & 100 & 100 \\
\hline
\end{tabular}


important aspects for practical application. As shown in Fig. 8(d), after continuous 2000 charge-discharge cycles at a large current density of $6 \mathrm{~A} / \mathrm{g}$ within a voltage range of 0.0 and $0.6 \mathrm{~V}$, the SC only decreased from ca. 439 to $415 \mathrm{~F} / \mathrm{g}$. Such a low SC degradation of ca. $6 \%$ reveals the good electrochemical stability of the composite.

It is well established that the electrochemical capacitance of an electroactive material is dependent upon its dimensions and microstructural texture. For the as-synthesized ordered mesoporous $\mathrm{NiO} /$ FCNTs composite, as depicted in Fig. 9, the FCNTs with their three-dimensional meso-/ macro- porous channels enhance the dispersion of the $\mathrm{NiO}$ phase greatly, reduce the diffusion length of the electrolyte ions, and ensure sufficient electrolyte ions rapidly contact the large surface areas of the electroactive $\mathrm{NiO}$. In particular, such a macroporous structure, due to its role as an "ion-buffering reservoir" [16], can sustain the supply of $\mathrm{OH}^{-}$ions and ensure that these ions diffuse into the mesoporous channels of $\mathrm{NiO}$ (indicated by the green square in Fig. 9), resulting in sufficient Faradaic reactions taking place at high current densities for energy storage. It can thus ensure higher utilization and higher-rate charge/ discharge performance. The FCNTs substrate has almost no electrochemical activity in $\mathrm{KOH}$ solution in the range of 0 to $0.6 \mathrm{~V}$, as shown in Fig. 10, which has also been verified in our previous work [30]. The typical redox peaks are obviously contributed by the nickel grid, rather than the FCNTs. The part below the zero-current line marked by the rectangular

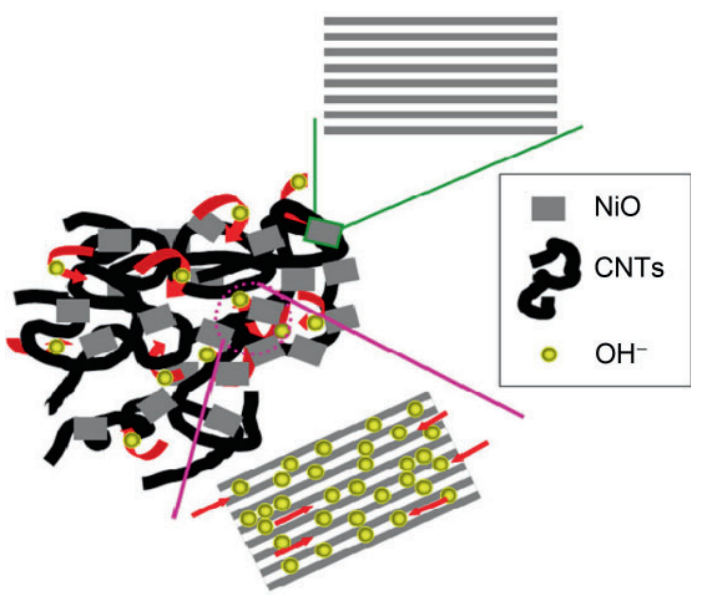

Figure 9 Schematic for the diffusion paths of $\mathrm{OH}^{-}$ions in the $\mathrm{NiO} /$ FCNTs composite

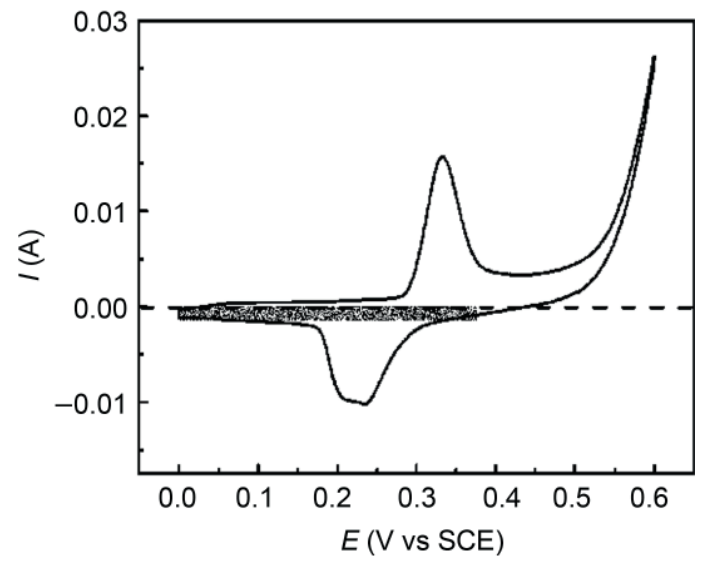

Figure $10 \mathrm{CV}$ curve of the FCNTs in $6 \mathrm{~mol} / \mathrm{L} \mathrm{KOH}(10 \mathrm{mV} / \mathrm{s})$

shadow is the electrochemical energy that the FCNTs can discharge and this energy is almost zero as indicated. Therefore, they mainly play the role of enhancing the conductivity of the composite, which can be verified by the electrical conductivity of ca. $10.3 \mathrm{~S} / \mathrm{cm}$ for the composite, as compared with that (ca. $0.1 \mathrm{~S} / \mathrm{cm}$ ) of the $\mathrm{NiO}$ synthesized without the addition of FCNTs.

To further support the above assertions, the electrochemical performance of the $\mathrm{NiO} / \mathrm{CNTs}$ composite was also investigated to illustrate the consequences of its three-dimensional meso-/macroporous channels being partially blocked by the $\mathrm{NiO}$ particles, as verified by its $\mathrm{N}_{2}$ adsorption-desorption isotherms and particle size distribution (PSD) data shown in Fig. 11.

As shown in Fig. 11(a), a distinct hysteresis loop can be observed in the lower pressure range of ca. 0.7-0.9 $P / P_{0}$, rather than the higher range observed for $\mathrm{NiO} / \mathrm{FCNTs}$, indicating the great decrease in the amount of macropores. Furthermore, the PSD of the NiO/CNTs composite, presented in Fig. 11(b), is centered in the mesoporous range from 2 to $50 \mathrm{~nm}$.

$\mathrm{CV}$ curves at various scan rates for the $\mathrm{NiO} /$ CNTs composite between 0.0 and $0.6 \mathrm{~V}$ (vs SCE) in $6 \mathrm{~mol} / \mathrm{L} \mathrm{KOH}$ aqueous electrolyte are shown in Fig. 12(a). The electrochemical responses are similar to those of the NiO/FCNTs composite shown in Fig. $8(a)$, which indicates that the same electrochemical reactions are responsible for its energy storage. Notably, the electrochemical response currents of the $\mathrm{NiO} / \mathrm{CNTs}$ are even less than those for the $\mathrm{NiO} /$ FCNTs composite, revealing the lower-energy storage

\section{Springer}




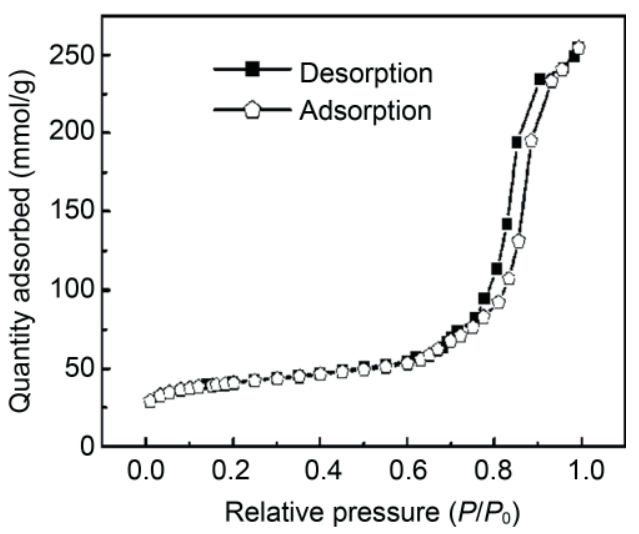

(a)

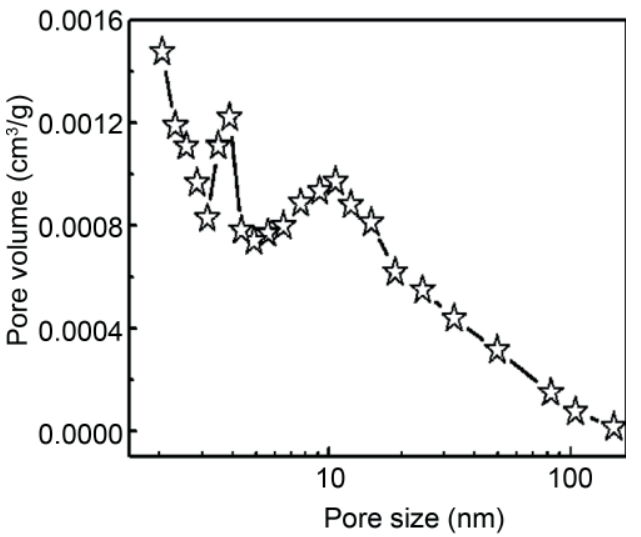

(b)

Figure 11 Gas $\left(\mathrm{N}_{2}\right)$ adsorption-desorption isotherm hysteresis loop (a) and histogram of the PSD data (b) for the NiO/CNTs composite

capacity of the NiO/CNTs composite. Figure 12(b) depicts the constant current charge-discharge curves of the $\mathrm{NiO} / \mathrm{CNTs}$ composite at various current densities as indicated within a potential range from 0.0 to $0.6 \mathrm{~V}$. Almost linear charge-discharge curves reveal its good supercapacitive performance. Furthermore, the SCs of the composite at various current densities can be calculated based on the charge-discharge curves in Fig. 12(b) according to Eg. (1) and typical data are shown in Table 2.

Careful comparison of the data shown in Tables 1 and 2 shows that all the SCs of the NiO/CNTs composite obtained from 1 to $6 \mathrm{~A} / \mathrm{g}$ are less than those delivered by the NiO/FCNTs composite at the same current density, the reasons for which can be related to the lower SSA of the $\mathrm{NiO} / \mathrm{CNTs}$ $\left(202 \mathrm{~m}^{2} / \mathrm{g}\right)$ and the fewer electrochemical reactions taking place in the $\mathrm{NiO} / \mathrm{CNT}$ s composite due to the deficiency of electrolyte ions at large currents. The $\mathrm{NiO}$ particle aggregation is response for both

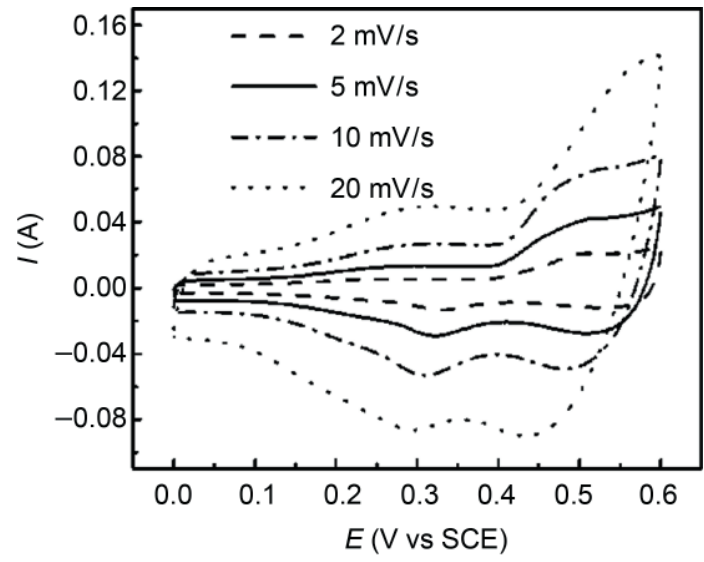

(a)

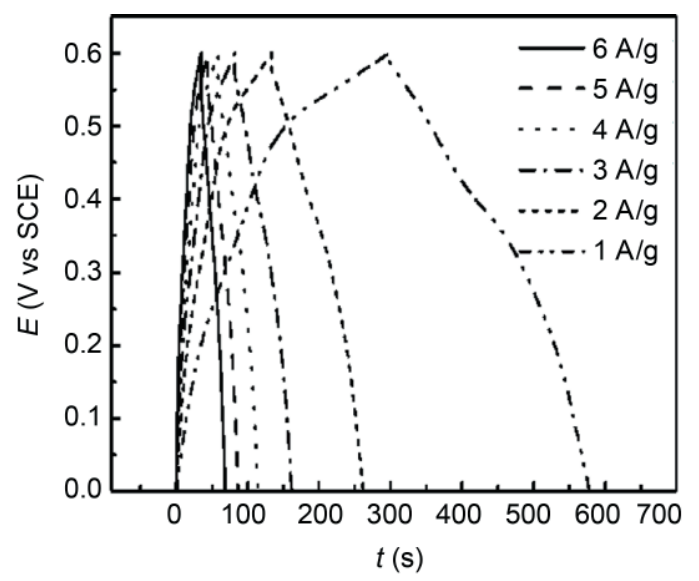

(b)

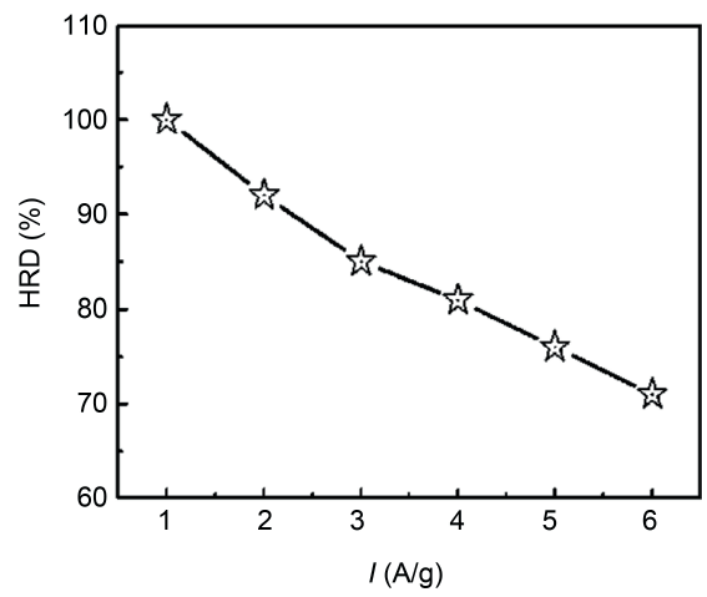

(c)

Figure 12 CV curves (a), CP plots (b) and HRD (c) of the NiO/CNTs composite

Table 2 SCS of the NiO/CNTs composite at different current densities

\begin{tabular}{ccccccc}
\hline$I(\mathrm{~A} / \mathrm{g})$ & 1 & 2 & 3 & 4 & 5 & 6 \\
\hline SC (F/g) & 466 & 428 & 396 & 378 & 356 & 332 \\
\hline
\end{tabular}


the decrease in SSA and the fewer electrolyte ions contacting the electroactive sites for energy storage. Besides the decrease in $\mathrm{SC}$, the HRD is also less than that of the NiO/PSS-CNTs, as shown in Fig. 12(c). The lower HRD of the $\mathrm{NiO} / \mathrm{CNTs}$ can be ascribed to the decrease in the number of macropores, because the electrical conductivity of the $\mathrm{NiO} / \mathrm{CNTs}$ is 13.5 $\mathrm{S} / \mathrm{cm}$, actually a little better than that of NiO/FCNTs. From the above discussion, it can be concluded that the existence of macropores plays a great role in the enhanced power properties of an electrode.

\section{Conclusions}

To recapitulate, we proposed for the first time a template-free synthetic approach for generating an ordered mesoporous NiO/FCNTs composite. The formation of the ordered mesoporous channels was confirmed to arise from the thermal decomposition of the corresponding precursor. Here, FCNTs, as a good three-dimensional conducting network, not only enhance the conductivity of the composite, but facilitate electrolyte soaking into particles, sustaining its supply, and creating many more porous channels for electrolyte ions to transport and electrochemically access more electroactive sites of the ordered mesoporous $\mathrm{NiO}$ for energy storage at larger current densities. Electrochemical tests demonstrated that the unique composite could deliver $439 \mathrm{~F} / \mathrm{g}$ at $6 \mathrm{~A} / \mathrm{g}$ with a low SC degradation of only ca. $6 \%$ after 2000 cycles, indicating the simultaneous achievement of large specific energy density, high specific power density, and good electrochemical stability. Moreover, the preparation we described here was carried out without using any template, which gives a simple and cost-effective route for large-scale production of the $\mathrm{NiO} / \mathrm{FCNTs}$ with good electrochemical capacitance for ECs application.

\section{Acknowledgements}

This work was supported by National Basic Research Program of China (973 Program) (2007CB209703), National Natural Science Foundation of China (20633040, 20873064), and the Graduate Innovation Plan of Jiangsu Province (CX07B-089Z).

\section{References}

[1] Hu, C. C.; Chang, K. H.; Lin, M. C.; Wu, Y. T. Design and tailoring of the nanotubular arrayed architecture of hydrous $\mathrm{RuO}_{2}$ for next generation supercapacitors. Nano Lett. 2006, 6, 2690-2695.

[2] Yuan, C. Z.; Chen, L.; Gao, B.; Su, L. H.; Zhang, X. $\mathrm{G}$. Synthesis and utilization of $\mathrm{RuO}_{2} \cdot \mathrm{xH}_{2} \mathrm{O}$ nanodots well dispersed on poly(sodium 4-styrene sulfonate) functionalized multiwalled carbon nanotubes for supercapacitors. J. Mater. Chem. 2009, 19, 246-252.

[3] Zheng, M. B.; Cao, J.; Liao, S. T.; Liu, J. S.; Chen, H. Q.; Zhao, Y.; Dai, W. J.; Ji, G. B.; Cao, J. M.; Tao, J. Preparation of mesoporous $\mathrm{CO}_{3} \mathrm{O}_{4}$ nanoparticles via solidliquid route and effects of calcination temperature and textural parameters on their electrochemical capacitive behaviors. J. Phys. Chem. C 2009, 113, 3887-3894.

[4] Xiong, S. L.; Yuan, C. Z.; Zhang, X. G.; Xi, B. J.; Qian, $Y$. T. Controllable synthesis of mesoporous $\mathrm{CO}_{3} \mathrm{O}_{4}$ nanostrucutres with tunable morphology for application in supercapacitors. Chem. Eur. J. 2009, 15, 5320-5326.

[5] Yuan, C. Z.; Gao, B.; Zhang, X. G. Electrochemical capacitance of $\mathrm{NiO} / \mathrm{Ru}_{0.35} \mathrm{~V}_{0.65} \mathrm{O}_{2}$ asymmetric electrochemical capacitors. J. Power Sources 2007, 173, 606-612.

[6] Nam, K. W.; Kim, K. B. A study of the preparation of $\mathrm{NiO}_{x}$ electrode via electrochemical route for supercapacitor applications and their charge storage mechanism. J. Electrochem. Soc. 2002, 149, A346A354.

[7] Xing, W.; Li, F.; Yan, Z. F.; Lu, G. Q. Synthesis and electrochemical properties of mesoporous nickel oxide. J. Power Sources 2004, 134, 324-330.

[8] Hu, C. Q.; Gao, Z. H.; Yang, X. R. Synthesis of mesoporous $\mathrm{NiO}$ with crystalline walls by a simple sol-gel route. J. Sol-Gel Sci. Technol. 2007, 44, 171-176.

[9] Yan, H. W.; Blanford, C. F.; Holland, B. T.; Parent, M.; Smyrl, W. H.; Stein, A. A chemical synthesis of periodic macroporous $\mathrm{NiO}$ and metallic Ni. Adv. Mater. 1999, 11, 1003-1006.

[10] Wang, Y. G.; Xia, Y. Y. Electrochemical capacitance characterization of $\mathrm{NiO}$ with ordered mesoporous structure synthesized by template SBA-15. Electrochim. Acta 2006, 51, 3223-3227.

[11] Yuan, C. Z.; Su, L. H.; Gao, B.; Zhang, X. G. Enhanced electrochemical stability and storage of $\mathrm{MnO}_{2} /$ carbon 
nanotubes composite modified by polyaniline coating layer in acidic electrolytes. Electrochim. Acta 2008, 53, 7039-7047.

[11] Lei, Y.; Fournier, C.; Pascal, J. L.; Favier, F. Mesoporous carbon-manganese oxide composite as negative electrode material for supercapacitors. Micropor. Mesopor. Mater. 2008, 110, 167-176.

[13] Li, J.; Yang, Q. M.; Zhitomirsky, I. Nickel foam-based manganese dioxide-carbon nanotube composite electrodes for electrochemical supercapacitors. J. Power Sources 2008, 185, 1569-1574.

[14] Park, J. H.; Park, O. O.; Shin, K. H.; Jin, C. S.; Kim, J. $\mathrm{H}$. An electrochemical capacitor based on a $\mathrm{Ni}(\mathrm{OH})_{2} /$ activated carbon composite electrode. Electrochem. Solid-State Lett. 2002, 5, H7-H10.

[15] Conway, B. E. Electrochemical Supercapacitors: Scientific Fundamentals and Technological Applications. Kluwer Acdemic/Plenum: New York, 1999.

[16] Wang, D. W.; Li, F.; Liu, M.; Lu, G. Q.; Cheng, H. M. 3D aperiodic hierarchical porous graphitic carbon material for high-rate electrochemical capacitive energy storag. Angew. Chem. Int. Ed. 2008, 47, 373-376.

[17] Nam, K. W.; Lee, E. S.; Kim, J. H.; Lee, Y. H.; Kim, K. B. Synthesis and electrochemical investigations of $\mathrm{Ni}_{1-x} \mathrm{O}$ thin films and $\mathrm{Ni}_{1-x} \mathrm{O}$ on three-dimensional carbon substrates for electrochemical capacitors. J. Electrochem. Soc. 2005, 152, A2123-A2129.

[18] Gao, B.; Yuan, C. Z.; Su, L. H.; Chen, S. Y.; Zhang, $X$. G. High dispersion and electrochemical capacitive performance of $\mathrm{NiO}$ on benzenesulfonic functionalized carbon nanotubes. Electrochim. Acta 2009, 54, 35613567.

[19] Zhang, H.; Cao, G. P.; Wang, Z. D.; Yang, Y. S.; Shi, Z. A.; Gu, Z. S. Growth of manganese oxide nanoflowers on vertically-aligned carbon nanotube arrays for high-rate electrochemical capacitive energy storage. Nano Lett. 2008, 8, 2664-2668

[20] Ye, J. S.; Cui, H. F.; Liu, X.; Lim, T. M.; Zhang, W. D.; Sheu, F. S. Preparation and characterization of aligned carbon nanotube-ruthenium oxide nanocomposites for supercapacitors. Small 2005, 1, 560-565.

[21]Zhang, M. N.; Su, L.; Mao, L. Q. Surfactant functionalization of carbon nanotubes (CNTs) for layer-by-layer assembling of CNT multi-layer films and fabrication of gold nanoparticle/CNT nanohybrid. Carbon
2006, 44, 276-283.

[22]Gong, K. P.; Yu, P.; Su, L.; Xiong, S. X.; Mao, L. Q. Polymer-assisted synthesis of manganese dioxide/carbon nanotube nanocomposite with excellent electrocatalytic activity toward reduction of oxygen. J. Phys. Chem. C 2007, 111, 1882-1887.

[23] Chen, L.; Yuan, C. Z.; Dou, H.; Gao, B.; Chen, S. Y.; Zhang, X. G. Synthesis and electrochemical capacitance of core-shell poly (3,4-ethylenedioxythiophene)/ poly(sodium 4-styrenesulfonate)-modified multiwalled carbon nanotube nanompocites. Electrochim. Acta 2009, 54, 2335-2341.

[24] O'Connell, M. J.; Boul, P.; Ericson, L. M.; Huffman, C.; Wang, Y. H.; Haroz, E.; Kuper, C.; Tour, J.; Ausman K. D.; Smalley, R. E. Reversible water-solubilization of singlewalled carbon nanotubes by polymer wrapping. Chem. Phys. Lett. 2001, 342, 265-271.

[25] Correa-Duarte, M. A.; Perez-Juste, J.; Sanchez-Iglesias, A.; Giersig, M.; Liz-Maran, L. M. Aligning Au nanorods by using carbon nanotubes as templates. Angew. Chem. Int. Ed. 2005, 44, 4375-4378.

[26] Lou, X. W.; Deng, D.; Lee, J. Y.; Archer, L. A. Thermal formation of mesoporous single-crystal $\mathrm{CO}_{3} \mathrm{O}_{4}$ nanoneedles and their lithium storage properties. J. Mater. Chem. 2008, 18, 4397-4401.

[27] Zhou, W.; Yao, M.; Guo, L.; Li, Y. M.; Li, J. H.; Yang, S. H. Hydrazine-liked convergent self-assembly of sophisticated concave polyhedrons of $\beta-\mathrm{Ni}(\mathrm{OH})_{2}$ and $\mathrm{NiO}$ from nanoplate building blocks. J. Am. Chem. Soc. 2009, 131, 2959-2964

[28] Matos, J. R.; Kruk, M.; Mercuri, L. P.; Jaroniec, M.; Zhao, L.; Kamiyama, T.; Terasaki, O.; Pinnavaia, T. J.; Liu, Y. Ordered mesoporous silica with large cage-like pores: Structural identification and pore connectivity design by controlling the synthesis temperature and time. J. Am. Chem. Soc. 2003, 125, 821-829.

[29] Grosso, D.; Illia, G.; Crepaldi, E. L.; Charleux, B.; Sanchez, C. Nanocrystalline transition-metal oxide spheres with controlled multi-scale porosity. Adv. Funct. Mater. 2003 $13,37-42$

[30]Su, L. H.; Zhang, X. G.; Liu, Y. Electrochemical performance of Co-Al layered double hydroxide nanosheets mixed with multiwall carbon nanotubes. J. Solid State Electrochem. 2008, 12, 1129-1134. 